\title{
Heat Illness. A Report of 45 Cases from Hong Kong
}

Major A Henderson, MRCP, RAMC, Consultant Physician

Major J W Simon, MRCS, DTM\&H, RAMC

Major W M Melia, MRCP(UK), RAMC

Major J F Navein,

MRCS, MRCGP, RAMC, GPVT

British Military Hospital, Hong Kong, BFPO I

Lt Col B G Mackay, *

DRCOG, MRCGP, RAMC, OC \& Gp Trnr

New Territories Group Practice Hong Kong

SUMMARY: During the summer of 1985,45 soldiers with heat illness were admitted to the British Military Hospital, Hong Kong. Twelve had severe heat stroke, the remainder heat exhaustion. This paper discusses the management and prevention of heat illness in the military context.

\section{Introduction}

The health hazard posed by high environmental temperature and humidity is frequently underestimated, yet, in the USA alone over 4000 heat related deaths are recorded annually ${ }^{1}$. Although the burden of mortality and morbidity falls on the elderly, young fit people, particularly soldiers undergoing vigorous training, may suffer severely ${ }^{2}$. Heat illness has a broad spectrum of severity. Mild cases (heat exhaustion) recover quickly with cooling and rehydration, whilst those with core temperatures greater than $41^{\circ} \mathrm{C}$ or cardiovascular or neurological complications (heat stroke) suffer a severe multisystem disorder with a mortality exceeding $50 \%{ }^{2-9}$.

Heat illness is caused by failure of the normal heat dissipation mechanisms allowing an excessive rise in core temperature. Once the core temperature exceeds $41^{\circ} \mathrm{C}$ protein denaturation begins ${ }^{7}$. Failure of adequate heat transfer to the environment is usually due to high environmental temperature or humidity although other factors such as excessive clothing and lack of air movement are important ${ }^{9}$. Other factors predisposing to heat illness are vigorous exercise, age, poor acclimatization, alcohol abuse, obesity, febrile illness, heart disease, drugs (especially atropine and phenothiazines) and inadequate fluid intake ${ }^{2,9-12}$.

The hot humid conditions which prevail during the Hong Kong summer have long been recognised as posing an environmental heat threat to military operations. The British Army uses the Wet Bulb-Globe Temperature Index (WBGT Index) to predict the severity of the heat threat ${ }^{13}$. It is calculated by the addition of $70 \%$ of the wet bulb temperature to $20 \%$ of the black bulb temperature plus $10 \%$ of the dry bulb temperature. The implications of the WBGT Index for military operations in Hong Kong are shown in Table 1.

This paper reviews all the heat illness casualties treated in the British Military Hospital (BMH) Hong Kong during 1985.

\section{Method}

All heat casualties admitted to BMH Hong Kong during 1985 were studied prospectively. They were assessed on admission according to a detailed protocol and assigned to one of two groups:

\section{a. Heat Exhaustion}

Defined as a rectal temperature of under $41^{\circ} \mathrm{C}$, normal peripheral perfusion, normal blood pressure and clear mentation or mild confusion. Immediate investigations included thick film examination for malarial parasites, serum urea and electrolytes, white cell count and packed cell volume.

\section{b. Heat Stroke}

Defined as a rectal temperature of over $41^{\circ} \mathrm{C}$ or lesser degrees of pyrexia in association with severe confusion, unconsciousness, hypotension or peripheral circulatory failure. Immediate investigations included thick film analysis for malarial parasites, serum urea and electrolytes, blood glucose, prothrombin time, fibrinogen degradation products, liver function tests, packed cell volume, white cell count, platelet count, serum creatine phosphokinase and hydroxybutyrate dehydrogenase, a chest X-ray and a 12 lead electrocardiogram. Further investigations such as blood gas analysis were done as indicated. Treatment was standardised using a predetermined heat illness protocol. 
Table I

Implications of the WBGT Index in Hong Kong

\begin{tabular}{lll}
\hline Heat Index & Acclimatised troops & Unacclimatised troops \\
\hline $26^{\circ} \mathrm{C}($ Green $)$ & Normal Work & Use discretion \\
\hline $28^{\circ} \mathrm{C}($ Amber $)$ & Use discretion & $\begin{array}{l}\text { Avoid work for the } \\
\text { first 7 days }\end{array}$ \\
\hline $30^{\circ} \mathrm{C}($ Red $)$ & Use discretion & $\begin{array}{l}\text { Avoid work for the } \\
\text { first 21 days }\end{array}$ \\
\hline $32^{\circ} \mathrm{C}$ or above & Avoid heavy & Avoid heavy \\
(Black) & exercise & exercise \\
\hline
\end{tabular}

On recovery all British and Gurkha soldiers were questioned about water discipline and their general knowledge of the environmental heat threat.

\section{Results}

A total of 45 male soldiers with heat illness were admitted to the study. All the casualties occurred during the hot humid summer between August and early November. They had all collapsed during or immediately after a period of vigorous physical exercise and all but two were evacuated to hospital by helicopter. They fell into three well defined groups which will be considered separately.

\section{Group 1: Casualties from an Australian Army Exercise}

During August (the hottest and most humid month in Hong Kong) the Australian Army held a company strength exercise involving an assault on a hill. The exercise began in the late morning when the WBGT Index was AMBER. Twenty-two men collapsed during the assault. They were doused with water, but not stripped, then evacuated to hospital by helicopter. All 22 arrived within a two hour period. None had their body temperature measured in the field. On arrival they were all lucid or only slightly confused, normotensive and normothermic. All were given a litre of normal saline intravenously and allowed free access to iced Dioralyte (Armour Pharmaceuticals: one sachet made up to $200 \mathrm{mls}$ with water contains sodium chloride 200 $\mathrm{mg}$, potassium chloride $300 \mathrm{mg}$, sodium bicarbonate 300 $\mathrm{mg}$ and glucose $8 \mathrm{~g}$.). They all recovered quickly and were discharged within 48 hours.

\section{Group II: Casualties from Exercise Bulldog Patrol}

Between the seventh and tenth of October Gurkha Field Force held a major exercise in the New Territories. The exercise finished with a forced march followed by a $2 \frac{1 / 4}{4}$ mile speed march carrying full equipment. The WBGT Index for the first two days of the exercise was unavailable due to a machine fault, Amber on Day 3 and Green on Day 4. A total of 18 serious heat casualties occurred during or immediately after the speed march All were taken to a nearby medical centre where the were stripped, covered in a wet sheet and vigorously fanned. Intravenous rehydration was started immedif tely using Hartmann's solution. The casualties were thet rapidly evacuated to hospital by helicopter. The medn delay between arrival at the medical centre and admission to hospital was 45 minutes (range 150 minutes).

\section{Clinical Features (See Table II)}

All had a short prodrome of headaches, craneppo nausea or vomiting, dizziness or irrational behavnog before collapsing. Eleven were seriously ill gith established heat stroke. Of these, three were confused, one was delirious and two were unconsche and unresponsive to painful stimuli. Three had rect temperatures of $42^{\circ} \mathrm{C}$ or higher. First aid at the point 9 collapse and the cooling effect of the helicopter flight produced a fall in rectal temperature in every case. $\overrightarrow{\overrightarrow{0}}$

There was a striking difference in the clinicæl condition of the British soldiers compared with the Gurkhas despite similar thermal insult. All the Britisi soldiers were, on arrival, mentally clear, normotensie and well perfused peripherally. Of the Gurkhas contrast six had severely impaired mental function (t in coma) and although normotensive or neक्के normotensive six were grossly vasoconstricted with codㅝㄹ cyanosed peripheries despite an elevated cor⿸厂⿱一兀) temperature.

Patients with rectal temperatures above $38^{\circ} \mathrm{C}$ wek cooled by tepid sponging and vigorous fanning. Onf the rectal temperature fell below $38^{\circ} \mathrm{C}$ active cooling wâs stopped to prevent an afterdrop in core temperature. Rehydration was with intravenous normal salife (infused cooled for patients still pyrexial) followed soon as possible by oral Dioralyte. All were significants dehydrated (See Table III) and some did not producs urine until more than two litres of intravenous fluid hat been infused. In patients with depressed consciousnest or peripheral circulatory failure urinary catheters weke 
Table II

Clinical data from heat casualties during Exercise Bulldog Patrol

\begin{tabular}{|c|c|c|c|c|c|c|c|c|c|}
\hline Patient & Diagnosis & Race & $\begin{array}{l}\text { Temperature } \\
\text { Medical } \\
\text { Centre } \\
\end{array}$ & $\begin{array}{l}{ }^{\circ} \mathbf{C} \\
\text { BMH }\end{array}$ & $\begin{array}{l}\text { MentaI } \\
\text { State }\end{array}$ & $\begin{array}{l}\text { Peripheral } \\
\text { Vasoconstriction }\end{array}$ & $\begin{array}{l}\text { Peripheral } \\
\text { Cynosis }\end{array}$ & $\begin{array}{l}\text { BP } \\
\text { at BMH } \\
(\mathrm{mm} \mathrm{Hg}) \\
\end{array}$ & ECG \\
\hline 23 & HS & $\mathrm{G}$ & 40.5 & 39.0 & Coma & Severe & Severe & $120 / 70$ & Normal \\
\hline 24 & HS & $\mathrm{G}$ & 41.8 & 38.0 & Normal & Absent & Absent & $110 / 70$ & Abnormal \\
\hline 25 & HS & $\mathrm{G}$ & 42.0 & 39.0 & Confused & Absent & Absent & $80 / 50$ & Abnormal \\
\hline 26 & HS & $\mathrm{G}$ & 42.4 & 37.5 & Normal & Severe & Severe & $110 / 70$ & Abnormal \\
\hline 27 & HS & G & 40.6 & 37.5 & Coma & Severe & Severe & $100 / 60$ & Abnormal \\
\hline 28 & HS & $\mathrm{G}$ & 41.5 & 38.0 & Confused & Severe & Severe & $125 / 70$ & Abnormal \\
\hline 29 & $\mathrm{HE}$ & $\mathrm{G}$ & 40.5 & 37.5 & Normal & Absent & Absent & $100 / 60$ & Normal \\
\hline 30 & HS & G & 39.5 & 37.5 & Confused & Severe & Severe & $120 / 90$ & Normal \\
\hline 31 & HE & B & 39.5 & 37.1 & Normal & Absent & Absent & $130 / 70$ & Normal \\
\hline 32 & HS & B & 41.7 & 38.5 & Normal & Absent & Absent & $130 / 70$ & Normal \\
\hline 33 & HS & $\mathrm{G}$ & 39.4 & 37.0 & Confused & Severe & Severe & $130 / 80$ & Normal \\
\hline 34 & HS & B & 42.4 & 37.5 & Normal & Absent & Absent & $130 / 70$ & Normal \\
\hline 35 & $\mathrm{HE}$ & B & 39.6 & 36.5 & Normal & Absent & Absent & $110 / 70$ & Normal \\
\hline 36 & HS & B & 41.0 & 37.0 & Normal & Absent & Absent & $130 / 70$ & Normal \\
\hline 37 & $\mathrm{HE}$ & B & 38.5 & 37.5 & Normal & Absent & Absent & $120 / 70$ & Normal \\
\hline 38 & HE & B & 39.5 & 38.0 & Normal & Absent & Absent & $115 / 80$ & Normal \\
\hline 39 & $\mathrm{HE}$ & $\mathrm{G}$ & 39.5 & 38.5 & Normal & Absent & Absent & $120 / 70$ & Abnormal \\
\hline 40 & $\mathrm{HE}$ & G & 38.5 & 37.5 & Normal & Absent & Absent & $110 / 80$ & Normal \\
\hline
\end{tabular}

passed, and blood gas analysis was used to assess acid base balance and the adequacy of gas exchange. Although oxygen was given to all these patients, none required mechanical ventilation.

Active cooling invariably caused severe shivering despite a raised core temperature. This was abolished by intravenous chlorpromazine $25 \mathrm{mg}$ repeated up to 75 mg with meticulous blood pressure monitoring. Patients such as case 23 could not initially be cooled by simple surface cooling methods because of gross peripheral circulatory failure which could not be reversed by rehydration. Incremental doses of chlorpromazine given as for shiver suppression produced sufficient cutaneous vasodilatation to allow cooling without having to resort to more invasive techniques such as cold peritoneal dialysis.

The British soldiers responded quickly to cooling and rehydration and all were fully recovered and discharged within three days. The Gurkhas by contrast had an average hospital stay of seven days (range 2-11 days). There were no deaths.

\section{Biochemical Data (See Table III)}

All patients had received at least one litre of Hartmann's solution before arrival at hospital. Serum sodium and potassium were normal. Serum urea was modestly raised and normalised in every case after rehydration. The mean serum urea in the Gurkhas was slightly but significantly higher than in the British soldiers (mean urea of $8.1 \mathrm{mmo1} / 1$ versus $6.8 \mathrm{mmo} 1 / 1$. $\mathrm{T}=0.8 \mathrm{p}<0.05)$. Liver function tests and muscle enzymes were measured in men with heat stroke. Serum bilirubin was normal in all cases. Aspartate transaminase (normal 5-50 iu/1) was raised in 10 (maximum value $108 \mathrm{iu} / \mathrm{l}$ ), alanine transaminase (normal 5-50 iu/l) was raised in one to $85 \mathrm{iu} / 1$, hydroxybutyrate dehydrogenase (normal 52-222 iu/1) was raised in seven (maximum value $307 \mathrm{iu} / 1$ ) and creatine phosphokinase (normal 45-390 iu/1) was raised in three (maximum value $673 \mathrm{iu} / 1$ ).

\section{Haematological Data (See Table III)}

All had modest neutrophil leucocythosis; the mean white cell count was $14.0 \times 10^{9} / 1$ (range $6.8-25.2 \times$ $10.9 / 1)$. None had a clinically important bleeding diathesis although three had prolongation of prothrombin time (up to 35 seconds) and one had slightly elevated fibrinogen degradation products (up to 40). These abnormalities disappeared within 48 hours. Platelets remained normal in every case. 
Table III

Biochemical and haematological data from Bulldog Patrol heat casualties

\begin{tabular}{|c|c|c|c|c|c|c|c|c|c|c|c|c|c|c|c|c|c|c|}
\hline Patient & 23 & 24 & 25 & 26 & 27 & 28 & 29 & 30 & 31 & 32 & 33 & 34 & 35 & 36 N̦ & 37 & 38 & 39 & 40 \\
\hline $\begin{array}{l}\text { Serum } \\
\text { Urea } \\
\text { mmol/1 }\end{array}$ & 5.8 & 4.7 & 7.2 & 9.4 & 6.7 & 9.5 & 9.2 & 9.2 & 5.0 & 7.5 & 10.6 & 7.1 & 6.1 & 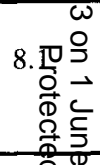 & 7.3 & 6.6 & 8.6 & 7.9 \\
\hline $\begin{array}{l}\text { Serum } \\
\text { Sodium } \\
\text { mmo1/1 }\end{array}$ & 144 & 139 & 146 & 138 & 139 & 140 & 142 & 141 & 138 & 140 & 145 & 139 & 136 & 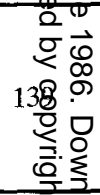 & 142 & 138 & 137 & 142 \\
\hline $\begin{array}{l}\text { Serum } \\
\text { Potassium } \\
\text { mmo1/1 }\end{array}$ & 4.7 & 5.0 & 4.5 & 4.6 & 5.3 & 4.3 & 4.7 & 4.2 & 5.9 & 4.5 & 4.5 & 5.4 & 3.6 & 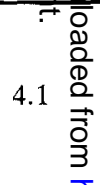 & 4.2 & 5.1 & 4.7 & 4.6 \\
\hline $\begin{array}{l}\text { Packed } \\
\text { cell } \\
\text { volume }\end{array}$ & $43 \%$ & $46 \%$ & $48 \%$ & $46 \%$ & $43 \%$ & $47 \%$ & - & $40 \%$ & - & $43 \%$ & $44 \%$ & $44 \%$ & $42 \%$ & 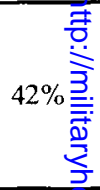 & $47 \%$ & $40 \%$ & $43 \%$ & $47 \%$ \\
\hline $\begin{array}{l}\text { White } \\
\text { cell } \\
\text { count } \\
\times 10^{9} / \mathrm{L}\end{array}$ & 9.5 & 17.2 & 11.1 & 12.1 & 11.0 & 22.1 & 16.7 & 16.0 & 16.8 & 16.0 & 25.2 & 12.3 & 20.7 & 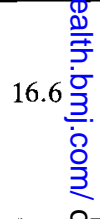 & 17.1 & 20.6 & 12.7 & 21.3 \\
\hline $\begin{array}{l}\text { Normal Values } \\
\text { Urea } 2.8-7 . \\
\text { White cell count }\end{array}$ & $\begin{array}{l}2 \mathrm{mmo} 1 \\
4-11\end{array}$ & $\begin{array}{l}/ / \mathrm{L} \\
\times 10^{9} / \mathrm{I}\end{array}$ & $\begin{array}{l}\text { Sodiur } \\
\text { L }\end{array}$ & $130-$ & $142 \mathrm{~mm}$ & $1 / \mathrm{L}$ & Potass & $\mathrm{m} 3.5$ & $5.00 \mathrm{I}$ & $\mathrm{mol} / \mathrm{L}$ & Pac & d cel & olume & 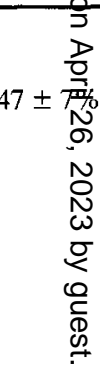 & & & & \\
\hline
\end{tabular}


Electrocardiography (See Table II)

The ECG remained normal in 12 . Six patients (all Gurkhas) had evolving ECG changes which were maximal between 48-72 hours. These changes comprised inferior ST segment depression and T wave inversion or anterior ST segment elevation with upward coving and $T$ wave flattening or inversion in a manner reminiscent of acute subendocardial infarction. The changes were not associated with chest pain or arrhythmias and had normalised in all but one case by 14 days. In all six, resting myocardial thallium scans were carried out during the third week but no abnormalities were detected.

\section{Water Discipline}

The British soldiers had all drunk between two and four litres of fluid during the forced march and had had compulsory stops for cooling and fluid replenishment. The Gurkhas had all drunk before the march and had not included water stops during the march and had been advised against drinking during heavy exercise. Seven had drunk no fluid at all while four had drunk up to $1 / 2$ litre.

\section{Knowledge of heat illness}

The British soldiers were all aware of the heat hazard but underestimated its magnitude. They had all heard of the heat illness immediate action drill, although in four of the seven their knowledge was inadequate. The Gurkhas seemed to be only dimly aware of the environment heat hazard and none knew the heat illness immediate action drill.

\section{Pre-existing Illness}

Three of the heat victims had "flu-like" symptoms within 24 hours of the exercise but none had reported sick. One Gurkha (case 23) suffered a relapse of fever on the day after admission. Examination revealed 2 small eschar and splenomegaly. A clinical diagnosis o scrub typhus was made and he responded rapidly to doxycycline.

\section{Disposal}

Following recovery all were subject to restrictions determined by the severity of their illness:

Heat exhaustion: no strenuous exercise for two weeks Heat stroke: no strenuous exercise for four weeks Abnormal ECG: medically downgraded to P3 for three months with a prohibition on strenuous exercise during that period.

\section{Group III. Sporadic Cases (See Table IV)}

Five men not involved in major exercises suffered heat' illness. All had been exercising vigorously before collapsing. Four had heat exhaustion and recoverech quickly on cooling and rehydration; they had taken large' volumes of fluid while exercising. One Gurkha (case 45 w had severe heat stroke; he collapsed after a run duri 79 which he had drunk nothing. He was not given first fid at the point of collapse and did not reach the medieas centre until half an hour later. He was then deefly unconscious with a rectal temperature of $38.5^{\circ} \mathrm{C}$. He stripped, cooled and given a litre of intravengiso Hartmann's solution before being taken by helicoptegado hospital. Despite rapid cooling and rehydration

Table IV

Haematological and Biochemical data from sporadic heat illness victims

\begin{tabular}{llllllll}
\hline Patient & Diagnosis & $\begin{array}{l}\text { Serum } \\
\text { Urea } \\
\text { mmo1/l }\end{array}$ & $\begin{array}{l}\text { Serum } \\
\text { Sodium } \\
\mathbf{m m o 1 / 1}\end{array}$ & $\begin{array}{l}\text { Serum } \\
\text { Potassium } \\
\mathbf{m m o 1} / \mathbf{l}\end{array}$ & $\begin{array}{l}\text { Packed } \\
\text { cell } \\
\text { volume }\end{array}$ & $\begin{array}{l}\text { White } \\
\text { cell } \\
\text { count } \\
\times \mathbf{1 0} / \mathbf{l}\end{array}$ & Race \\
\hline 41 & HE & 6.1 & 138 & 4.2 & 39 & 18.3 & B \\
\hline 42 & HE & 8.5 & 144 & 4.7 & 55 & 12.6 & B \\
\hline 43 & HE & 3.8 & 140 & 3.8 & 43 & 6.8 & $\mathrm{G}$ \\
\hline 44 & HE & 10.6 & 142 & 4.4 & 47 & 23.7 & $\mathrm{G}$ \\
\hline 45 & HS & 7.8 & 141 & 4.1 & 36 & 10.3 & $\mathrm{G}$ \\
\hline
\end{tabular}

Normal Values

Sodium $130-142 \mathrm{mmol} / \mathrm{L}$

White Count $4-11 \times 10^{9} / \mathrm{L}$

Packed cell volume $47 \pm 7 \%$
Urea $2.8-7.2 \mathrm{mmol} / \mathrm{L}$

Potassium $3.5-5.0 \mathrm{mmol} / \mathrm{L}$
HS = Heat Stroke

HE = Heat Exhaustion

$\mathbf{G}=$ Gurkha

$\mathbf{B}=$ British 
hospital he remained very drowsy for three days. Further examination revealed gross truncal ataxia and dysarthria. A cerebral CAT scan was normal and viral titres (including Japanese encephalitis) were negative. His CSF was normal except for a slightly elevated protein $(1.2 \mathrm{~g} / 1)$. He gradually recovered over six weeks.

\section{Discussion}

The heavy toll of heat casualties provided not only experience in the management of heat illness of all grades of severity but highlighted several problem areas.

\section{The Multiple Casualty Situation}

Heat illness is not often thought of as a cause of multiple casualties yet its potential in this regard was amply shown by both the Australian and British Army exercises. During the Australian exercise all 22 casualties were admitted within a short time. Their early assessment and management was greatly eased by the existence of a standardised policy (Heat Illness Protocol) for the triage, investigation and management of heat victims. Using the protocol, junior doctors, inexperienced in heat illness, and senior nursing staff could begin essential investigations and treatment without having to wait for advice from a senior colleague.

The multiple casualty situation during Bulldog Patrol was different and more complex in that 3-5 seriously ill patients arrived together on each of four consecutive days. A senior doctor was assigned to the intensive care unit to supervise resuscitation. As the intensive care facility became full, further direct admissions were stopped. New arrivals were assessed in an adjacent room by another experienced doctor before being transferred to the general ward or intensive care for resuscitation and treatment. Here again the standardised Heat Illness Protocol was invaluable in providing guidance for junior doctors and nurses at a time when senior colleagues were fully occupied with gravely ill patients.

\section{Management of Heat Illness in the field}

The duration of hyperpyrexia is a crucial prognostic factor ${ }^{2,9}$. Prompt first aid in the field can do much to prevent mortality and permanent neurological sequelae in heat victims. The speed of cooling is more important than the method. During the Australian exercise, sensible measures at the point of collapse probably prevented heat stroke in some men, whilst during Bulldog Patrol more sophisticated measures taken at the nearby medical centre probably saved lives of some of the worst cases. At the most basic level, the victim should be removed to a shaded, cool place, stripped off and fanned. If water is available, dousing the victim enhances cooling. Those capable of drinking should be encouraged to do so, although depressed consciousness and nausea are limiting factors. At a more sophisticated level rapid intravenous rehydration will mitigate the worst effects of heat illness. Transportation to hospital by helicopter has the advantage of speed and produces rapid cooling due to draught. It was our impression that the more open Scout helicopter produced better cooling than the Wessex. In the absence of a helicopter, a vehicle with a covered roof and open sides will produce effective cooling, particularly if the victim is wrapped in a wet sheet ${ }^{11}$.

\section{Management of Heat Exhaustion in Hospital}

Providing that victims are rapidly cooled and rehydrated full recovery within 48 hours can be expected. We found stripping, tepid sponging and vigorous fanning to be an effective method of cooling. Although many patients will achieve water and electrolyte homeostasis if given free access to oral fluids (we used Dioralyte) some are intolerant to oral rehydration because of nausea and vomiting. This is especially troublesome in patients who have experienced severe salt depletion ${ }^{2,11}$. To avoid this we routinely used intravenous rehydration in addition to free oral fluids during the first 12 hours.

\section{Management of Heat Stroke in Hospital}

All patients with established heat stroke were admitted to the intensive care unit because of the risk of sudden death ${ }^{7}$ and the everpresent threat of complex multisystem failure.

\section{Cooling}

Stripping, tepid sponging and fanning were used as a routine and were effective in patients without peripheral circulatory failure. Large volumes of chilled normal saline were held in the intensive care unit for early resuscitation of hyperpyrexial patients. Even in the presence of a raised core temperature active cooling invariably produced a highly undesirable heatproducing shiver response. Shivering was abolished by intravenous chlorpromazine $25 \mathrm{mg}$ repeated up to 75 $\mathrm{mg}^{2,9,11,14}$. It is vital to delay using chlorpromazine until intravenous fluid repletion is underway to avoid hypotension. Blood pressure must be monitored very frequently.

Recently it has been shown that very rapid cooling can be achieved by placing the victim on an open string mattress and spraying atomised water driven by warm air from above and below ${ }^{15}$. Methods which rely upon surface cooling can not be used alone in hyperpyrexial patients with profound cutaneous vasoconstriction due to peripheral circulatory failure. We found using chlorpromazine as for shiver supression produced sufficient cutaneous vasodilatation to allow surface cooling so avoiding more dangerous techniques such as cold peritoneal dialysis ${ }^{16}$. Active cooling was stopped once the rectal temperature fell below $38^{\circ}$ to avoid an undesirable after drop in core temperature ${ }^{2}$. 


\section{Rehydration}

All patients were rehydrated with intravenous normal saline. Urinary catheters were passed in patients with depressed consciousness or peripheral circulatory failure to monitor hourly urine flow. Some patients required more than two litres of intravenous fluid before any urine appeared. In our patients central venous pressure monitoring was not necessary although it was available.

\section{Management of Complications}

\section{Neurological.}

Confusion is common ${ }^{2,1}$. Three patients in this study were very confused but all recovered without sequelae. One patient was severely disturbed and required sedation for 24 hours with intravenous chlorpromazine. On recovery he suffered troublesome headache for several days. Three patients were unconscious on admission. Coma can develop with remarkable speed in severe heat illness and is an ominous prognostic sign ${ }^{2,3}$. All survived although one suffered severe cerebellar dysfunction which persisted for several weeks. Permanent neurological damage may occur and was probably averted in this series by early aggressive treatment ${ }^{2,9,11,17}$. In patients with severely disturbed consciousness alternative diagnoses such as cerebral malaria, meningitis, encephalitis or hypoglycaemia should not be forgotten.

\section{Cardiovascular}

Six patients had profound peripheral circulatory failure with cold cyanosed extremities. Despite normal or near normal blood pressure peripheral circulatory failure in the context of heat stroke implies a grossly reduced cardiac output (under 3 litres $/ \mathrm{min} / \mathrm{m}^{2}$ ) and is a bad prognostic sign ${ }^{2,18,19}$. Its mechanism is complex. With core temperatures above $41^{\circ} \mathrm{C}$ direct myocardial depression occurs ${ }^{20}$ but a more important mechanism appears to be hypovolaemia due to excessive sweating, leakage of fluid across capillary membranes rendered incompetent by heat injury and inadequate fluid intake $e^{9,21}$. They responded poorly to volume replacement and oxygen therapy. Small repeated doses of intravenous chlorpromazine reduced the intensity of the vasoconstriction and improved urine flow. Specific inotropes such as dopamine were not necessary.

Serial ECG monitoring revealed evolving changes suggestive of subendocardial infarction in six Gurkhas. None had been significantly hypotensive but three had severe peripheral circulatory failure on admission.

This type of electrocardiographic pattern has been described by others and the changes may persist for months $3,8,18,22,23$. In fatal cases spotty myocardial necrosis is found $\mathrm{d}^{3,21,24}$ and this type of pathology may have been responsible for the ECG changes in our series. The normal myocardial thallium scans excluded large areas of necrosis but the method is probably too insensitive to detect very small areas of necrosis.
Collateral evidence of infarction can not be obtaine from assay of cardiac enzymes as these may be elevates after heavy exertion and in patients with heat strok 8 without other evidence of myocardial injury ${ }^{25}$.

\section{Haematological Abnormalities}

A neutrophil leucocytosis is a feature of heat illne. and was present in all patients in this series. It has n\& significance beyond realising that it does not impla bacterial infection ${ }^{11}$. Minor derangements of clotting ar. common but as in this series, they are usually of littio clinical importance $3,4,8,9,26$. Major bleeding due to disseminated intravascular coagulation has beeds described and appears to respond to clotting factor replacement and heparin ${ }^{2,6,26}$.

\section{Metabolic Complications}

Mild metabolic acidosis was common but responde to intravenous fluid replacement, and specific therap with bicarbonate was not required. Although the fluid and electrolyte status of patients depends upon the quantity of fluids drunk most patients have a combine $\$$ water, sodium and potassium deficiency ${ }^{2,8}$. We routinel's used normal saline to replace circulating volume ang added potassium chloride to the intravenous fluids a as soon as patients began to pass urine. None of golut patients developed oliguric or polyuric renal failire although both are well known complications of heat stroke $^{\mathbb{0}, 27,28}$.

The liver is very sensitive to heat injury and 1 oo chemical evidence of liver damage is common ${ }^{2,21}$. Aim our series it is usually of little clinical significa although occasionally it may be severe enough contribute to death ${ }^{21}$.

\section{Prevention of Heat Illness}

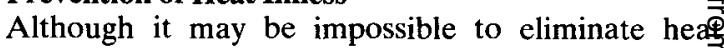
illness from military operations in the tropics much can be done to reduce its prevalence and severity.

WBGT Index. This provides commanders with a rapid assessment of the environment heat hazard (Table 1). is vital to realise however that indices below BLACK $\mathrm{d} \bar{\Phi}$ not equate with safety. Experience in Hong Kong during 1985 has shown an AMBER reading to be associate with a grave hazard.

Acclimatization. Although this was not a factor in ou patients it is a well recognised variable in the genesis of heat illness. The mechanism is complex but excessive sweat loss in unacclimatized people undergoing har $\bar{\oplus}$ physical training may be important ${ }^{9,11}$.

Timing of Exercise. Where possible strenuous exercise should be avoided during the hottest period o. the day ${ }^{11}$. This may not always be possible in the militar context but the penalty can be high as may be seen from? the heat casualties from the Australian Army Exercise.

Avoiding Dehydration. Heavy exercise in hot weathed causes enormous loss of water, sodium and potassium ip sweat. Peak sweating rates may exceed two litres pes 
hour ${ }^{2}$. During strenuous exercise adequate stops for cooling and rehydration are essential if heat illness is to be avoided ${ }^{2,9,11,21}$. Lack of proper water stops probably explains the extremely severe heat illness suffered by the Gurkha soldiers. Although giving additional salt had been advocated during heavy exercise, it appears that this is not only unnecessary, but potentially dangerous, as it may induce hypokalaemia ${ }^{2,11}$.

Increasing Knowledge of Heat Illness. The results of the questionnaire filled in by the heat victims from Bulldog Patrol showed a low level of knowledge regarding heat illness particularly with the Gurkhas. Caution however must be used in extrapolating this type of data to the battalions in general. Clearly it is essential that all soldiers are familiar with the heat illness immediate action drill. Commanders at all levels need to be aware of the prodromal symptoms of heat illness such as faints, dizziness, cramps, vomiting or unusual behaviour which although readily reversible with cooling and rehydration, can, if ignored, rapidly progress to fatal heat stroke ${ }^{11}$. If possible light open clothing should be worn although in the military context this may not always be possible ${ }^{9}$.

Pre-exisiting Febrile Illness. Febrile illness of any sort appears to predispose to heat illness ${ }^{11,30}$. Three men in this series had mild febrile symptoms within 24 hours of the exercise. None reported sick and excluding such highly motivated men from competitive events is difficult. Here education is vital. One man, who suffered severe heat stroke, was in the early stages of scrub typhus during the exercise and although feeling unwell felt unable to withdraw because of regimental pride.

Recent experience in Hong Kong has shown the continuing dangers to soldiers from high ambient temperatures. Much can be done to prevent heat illness by more extensive education of those exposed to the heat hazard and those supervising soldiers.

\section{Acknowledgment}

Assistance of Pathology Laboratory headed by Lt Col S H Ali and Capt A J Baronne, in producing the host of biochemical data is gratefully acknowledged.

\section{REFERENCES}

1. SCHUMAN S H. Patterns of urban heat wave deaths and implications for prevention: data from New York and St Louis during July 1966. Environ Res 1972; 5: 59-75.

2. Clowes G H A and O'Donnell T F. Current Concepts: Heat Stroke. New Eng J Med 1974; 291: 564-567.

3. Malamud N, Haymaker $W$ and Custer BP. Heat Stroke: a clinicopathologic study of 125 fatal cases. Milit Surg 1946; 99: 397-449.

4. Ferris E B Jr, Blankenhorn M A and Robinson $\mathrm{H}$ W et al. Heat Stroke: Clinical and chemical observation on 44 cases. J. Clin. Invest 1938; 17:249-262.

5. GAuss $\mathrm{H}$ and MEYER K A. Heat Stroke: A report of one hundred and fifty eight cases from Cook County Hospital, Chicago. Am J Med Sci 1917; 154: 554-564.
6. O'DONNELL T F Jr. Medical problems of recruit training: a research approach. US Navy Med 1971; 58: 28-34.

7. Wetherall D J, LedinghaM J G G and WarRell DA, (Eds). Oxford Textbook of Medicine. Oxford University Press. Oxford 1983; 6. 52-6.53.

8. KNOCHEL J P, BEISEL W R and HERndon E G et al. The renal, cardiovascular, haematologic and serum electrolyte abnormalities of heat stroke. Am J Med 1961; 30: 299-309.

9. Tinker J and Radin M (Eds). Care of the Critically Ill Patient. Springer Verlag. New York 1983; 865-868.

10. SCHRIER R W, et al. Renal, metabolic and circulatory responses to heat and exercise. Ann Intern Med 1970; 73: 213-223.

11. Shibolet S, Lancaster M C and Danon Y. Heat Stroke: A review. Aviat Space Environ Med 1976; 3: 280-299.

12. Harrison M H, Edwards R J and Leitch D R. Effect of exercise and thermal stress on plasma volume. J Appl Physiol 1975; 39: 925-931.

13. MinaRd D and O'Brien R L. Heat casualties in the Navy and Marine Corps 1959-1962 with appendices on the field use of the wet bulb-globe temperature index. US Naval Med Res Inst Rep 1964; 7: 1-15.

14. GotTsChalk P G and Thomas J E. Heat Stroke. Mayo Clin Proc. 1966; 41: 470-482.

15. Khogali M and Weiner J S. Heat Stroke: a report on 18 cases. Lancet 1980; II: 276-278.

16. GJessing J, BARSA J and TOMLIN P J. A possible means of rapid cooling in the treatment of Malignant Hyperthermia. BrJ Anaesth 1976; 48: 469-472.

17. Freeman $W$ and DumofF $S$. Cerebellar syndrome following heat stroke. Arch Neurol Psych 1944; 51: 67-72.

18. GoLD J. Development of heat pyrexia. J A M A 1960; 173: 1175-1182.

19. O'Donnell TF $\mathrm{Jr}$ and Clowes GHA Jr. The circulatory abnormalities of heat stroke. New Eng J Med 1972; 287: 734-737.

20. Moore F T, Marable S A and Ogden E. Contractility of the heart in abnormal temperatures. Ann Thorac Surg 1966; 2: 446-450.

21. KEW M, et al. Liver damage in heat stroke. Am J Med 1970; 49: 192-202.

22. Braunwald E (Ed). Heart Disease. Saunders (Pub) London 1980; 1489.

23. Kew M C, et al. The heart in heat stroke. Am Heart J $1969 ; 77: 324-335$.

24. WILSON G. The cardiopathy of heatstroke. J A MA 1940; 114: 557.

25. SOBEL B E and SHELL W E. Serum enzyme determination in the diagnosis and assessment of myocardial infarction. Circulation 1972; 45: 471.

26. Weber $M$ B and Blakely $J$ A. The haemorrhagic diathesis of Heat Stroke. Lancet 1969; 1: 1190-1192.

27. SobeL S, et al. Renal Mechanisms in heat stroke $J$ Clin Res 1963; 11: 252.

28. KEw M C, et al. The effects of heat stroke on the structure and function of the kidney. QJ Med 1967; 36: 277-300.

29. Vescia $F \mathrm{G}$ and PECK $\mathrm{O} C$. Liver disease from heat stroke. Gastroenterology 1962; 43: 340 .

30. Ferguson M and O'Brien M M. Heat stroke in New York City: Experience with 25 cases. NY State J Med 1960; 60: 2531-2538. 